\title{
Süstalinable Chemistry\& Engineering

\section{Versatility of a Dilute Acid/Butanol Pretreatment Investigated on Various Lignocellulosic Biomasses to Produce Lignin, Monosaccharides and Cellulose in Distinct Phases}

\author{
Quentin Schmetz, ${ }^{* \dagger}{ }^{\dagger}$ Hiroshi Teramura, ${ }^{\ddagger}$ Kenta Morita, ${ }^{\ddagger}$ Tomoko Oshima, ${ }^{\ddagger}$ Aurore Richel, ${ }^{\dagger}$ \\ Chiaki Ogino, ${ }^{\ddagger}$ and Akihiko Kondo \\ ${ }^{\dagger}$ Laboratory of Biomass and Green Technologies, Gembloux Agro-Bio Tech-University of Liege, Place du 20 Août 7, Liège, 4000, \\ Belgium \\ ${ }^{\ddagger}$ Department of Chemical Science and Engineering, Graduate School of Engineering, Kobe University, 1-1 Rokkodaicho, Nada-ku, \\ Kobe, Hyogo 657-8501, Japan \\ ${ }^{\S}$ RIKEN Center for Sustainable Resource Science, 1-7-22 Suehiro-cho, Tsurumi-ku, Kanagawa, Yokohama 230-0045, Japan
}

Supporting Information

ABSTRACT: An organosolv pretreatment consisting of an $\mathrm{H}_{2} \mathrm{SO}_{4} / n$-butanol biphasic system was designed to separate lignocellulosic biomass in three distinct phases: a cellulose-rich solid residue, hydrolyzed hemicelluloses in an aqueous phase, and lignin dissolved in a hydrophobic butanol phase. In the present study, the versatility of the process was investigated on materials of various compositions and origins: sugar cane bagasse, tall fescue, sugar beet pulp, eucalyptus, beech, and Japanese cedar. The efficiency was assessed in terms of lignin removal from the raw biomass and purity of the recovered cellulosic residue using the Klason method as well as improvement on enzymatic saccharification (increased from $18.7 \%$ to $96 \%$ ). Results were correlated to biomass types and composition, and in comparison to an organic solvent-free method (dilute acid). Up to $81 \%$ cellulose purity corresponding to $87 \%$ lignin removal was achieved. Results were corroborated by scanning electron microscopy showing an absence of lignin deposition. Lignin molecular weight (GPC), structure (2D-HSQC NMR), recovery, and purity (up to 96\%) have been investigated. Moreover, organic compounds responsible for fermentation inhibition were partially solubilized in

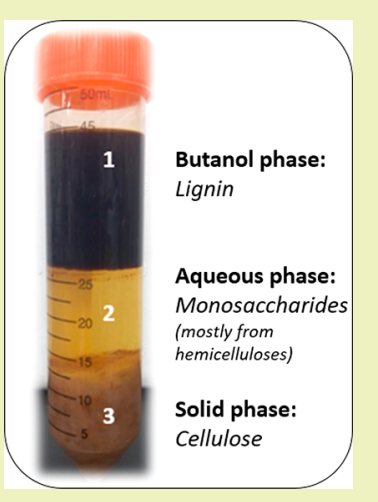
the butanol, decreasing the concentration in the aqueous phase. Efficient butanol pretreatment applied on hardwood, bagasse, and herbaceous matter is promising. However, Japanese cedar (softwood) was too recalcitrant for this process.

KEYWORDS: n-Butanol, Organosolv, Biphasic, Lignocellulose, Biocompounds, Saccharification

\section{INTRODUCTION}

A great deal of research has been conducted to switch the current economy dependent on fossil fuels to a more sustainable "bioeconomy." It particularly focuses on using renewable feedstock, including lignocellulosic biomass, which includes nonedible plant material composed of polysaccharides (cellulose and hemicelluloses) and a phenolic polymer, lignin. ${ }^{2,3}$ The development of biorefineries to produce biofuels and biomaterials from cellulose, hemicelluloses, and lignin from lignocellulosic biomass is constantly evolving. ${ }^{4-6}$

A fractionation step, called "pretreatment," is required to break up the complex structure of lignocellulose and allow the valorization of the different constituents. ${ }^{7}$ These processes can be divided into four fundamental categories: physical, physicochemical, chemical, and biological. ${ }^{7,8}$ The main goal of pretreatment is to increase the yield of fermentation products with respect to the initial biomass. A porous altered structure is obtained by destabilization/partial removal of lignin and hemicelluloses and by reducing cellulose crystallinity. ${ }^{9}$ Lignin content and composition have a significant impact on the recalcitrance. Native lignin and lignin that recondensates during the pretreatment cool-down phase decrease the access to cellulose by enzymes. ${ }^{10}$ It is therefore of importance to optimize treatment to prevent lignin condensation through chemical quenching or physical removal. ${ }^{11}$ The pretreatment conditions can also favor the degradation of monosaccharides and promote deacetylation, releasing byproducts that can have inhibitory effects on enzymes. ${ }^{7,8}$ One solution, among others, is the use of a biphasic reaction system containing a hydrophobic organic solvent and aqueous phase to physically separate cellulose from lignin and inhibitors during treatment. ${ }^{12}$ Among pretreatments, organosolv is a promising technology using an organic solvent to solubilize lignin. ${ }^{13,14}$ An efficient approach in a biorefinery is the coproduction of both materials from the cellulose fibers and added-value compounds from hemi-

Received: November 12, 2018

Revised: May 29, 2019

Published: June 12, 2019 
celluloses and lignin. ${ }^{11,12}$ Some recent studies focused on using biphasic systems to fractionate the biomass into cellulose, hemicelluloses, and lignin, in three distinct phases in a one-pot reactor approach. ${ }^{12}$ Among them, butanol was selected as a hydrophobic green solvent. ${ }^{15,16} \mathrm{~A}$ resurgence of interest in sustainable production of biobutanol ensured by biorefineries through fermentation by Clostridium acetobutylicum using renewable substrates (glucose) motivates this choice. ${ }^{17}$ Thereby, it is believed that its market value could change in a few years. ${ }^{18}$ The potential application of butanol as a green fuel explains recent attempts to revive a commercial butanol fermentation process. ${ }^{19}$ Butanol used for pretreatment has been demonstrated to achieve a similar delignification to ethanol, while requiring less solvent. ${ }^{15,20}$ Butanol is seen as an expensive solvent in terms of cost and energy consumption (boiling point: $117{ }^{\circ} \mathrm{C}$ and latent heat of vaporization: 43.72 $\mathrm{kJ} / \mathrm{mol}$ ) compared to conventional alcohols used in a monophasic system such as ethanol $\left(78.3{ }^{\circ} \mathrm{C}\right.$ and $38.91 \mathrm{~kJ} /$ $\mathrm{mol}$ ). Nevertheless, the separation and recycling of the solvent in a biphasic system need lower energy requirements than monophasic systems. This justifies the utilization of expensive solvents under optimum conditions that could still lead to profitable industrial processes. ${ }^{12}$

The recalcitrance of the biomass to the pretreatment and subsequent enzymatic saccharification is another factor that increases the overall cost of a process. It is known to be multifactorial and highly dependent on the nature of the biomass. ${ }^{13}$ This includes, among other things, the proportion and composition of lignin and hemicelluloses. ${ }^{21}$ In addition, the adsorption of soluble lignin after pretreatment onto enzymes has to be taken into account when valorizing the solubilized monosaccharides because of the decreasing activity generated. ${ }^{10}$ It is commonly accepted that the higher content of lignin in woody biomasses compared to herbaceous materials causes a stronger recalcitrance. In addition, the ratio of guaiacyl $(\mathrm{G})$, syringil $(\mathrm{S})$, and p-hydroxyphenyl $(\mathrm{H})$ units in lignin has an influence. Lignins from softwoods are more resistant than those from hardwoods due to their larger proportion of $\mathrm{G}$ units. ${ }^{22}$ Recent works are emerging that study pretreatment in biphasic systems. ${ }^{12}$ Among them, dilute acid/ $n$-butanol was investigated. ${ }^{15,16}$ However, a lack of knowledge concerning the effect of a butanol pretreatment according to the type of biomass points to the relevance of the present work. We proposed to investigate the versatility of such a dilute acid/ butanol pretreatment on six biomasses of various compositions and origins such as forest resources (eucalyptus, beech wood, Japanese cedar), agricultural residues (sugar cane bagasse, sugar beet pulp), and dedicated crops for biofuel production (tall fescue). The efficiency was assessed in terms of lignin removal from the raw biomass, the recovery, the structure and purity of recovered lignin, and cellulosic residue using the Klason method, as well as improvement on the enzymatic saccharification. Results were correlated to biomass types and composition and in comparison to a solvent-free method (dilute acid). Finally, distribution of fermentation inhibitors among liquid phases was assessed.

\section{EXPERIMENTAL SECTION}

Materials. Six raw biomasses have been selected for this study. Japanese cedar wood (JCW; Cryptomeria japonica) as a softwood model, eucalyptus wood (EUW) as a high lignin content hardwood model, and sugar cane bagasse (SCB) as an agricultural residue model were provided by Toyota Motor Corporation (Miyoshi, Japan).
Beech wood (BEW; Fagus sylvatica L.), as hardwood model, was collected in Ardennes, Belgium and crushed to chips $(2.3 \times 1.5 \times 0.3$ $\mathrm{cm}$ ) and dried at $50{ }^{\circ} \mathrm{C}$ for $24 \mathrm{~h}$.

Sugar beet pulp (SBP), as an industrial coproduct model, was obtained from Tirlemont sugar refinery (Südzucker Group).

Tall fescue (TFE; Festuca arundinacea Schreb.), as an herbaceous plant model, was seeded in experimental fields in Gembloux in Belgium at the end of August 2008. The field was harvested at the end of spring, end of summer, and end of autumn.

Biomasses were stored in a dry place at room temperature prior to and after the grinding using a Fritsch PULVERISETTE 19. Raw biomass samples were dried overnight in an oven at $80{ }^{\circ} \mathrm{C}$ prior to analysis and pretreatment.

Pretreatment. Dilute acid pretreatment (DAP) and butanol pretreatment (BUTP) were both performed under the same temperature and stirring conditions. ${ }^{23}$ Sulfuric acid $\left(\mathrm{H}_{2} \mathrm{SO}_{4}\right)$ and $n$ butanol were purchased at Nacalai Tesque (Kyoto, JAPAN). A laboratory-scale thermostirrer (HHE-19G-U $(100 \mathrm{~mL})$ ) was preheated to $180{ }^{\circ} \mathrm{C}$ prior to adding the Teflon vessel containing $6 \mathrm{~g}$ of ground biomass suspended in $80 \mathrm{~mL}$ of $\mathrm{H}_{2} \mathrm{SO}_{4} 1 \%$ [v/v] solution (DAP) or in $20: 60 \mathrm{~mL}$ of $n$-butanol $/ \mathrm{H}_{2} \mathrm{SO}_{4} 1 \%$ [v/v] solution (BUTP). Each experiment was conducted for $45 \mathrm{~min}$ of cooking time with magnetic agitation at $200 \mathrm{rpm}$. The medium was then left to cool to room temperature. Fractions obtained were then separated into an aqueous phase and solid fraction by filtration using filter paper in the case of DAP. In the case of BUTP, centrifugation at $9850 \mathrm{~g}$ for $15 \mathrm{~min}$ using a Kubota 3740 centrifuge was performed prior to the filtration to separate the solid fraction and the two nonmiscible liquid fractions, namely butanol and aqueous fractions. The butanol fraction was separated from the aqueous fraction for quantification of lignin and organic compounds. The aqueous phase and solid fraction were then separated through DAP. The recovered butanol fraction was diluted three times to precipitate lignin in solution, and it was recovered by centrifugation during $4 \mathrm{~min}$ at $2330 \mathrm{~g}$. The supernatant was discarded, and pellets were freeze-dried using a FreeZone 2.5 (Labconco) system. Both DAP and BUTP solid fractions were washed with deionized water until attaining a neutral $\mathrm{pH}$ and dried at room temperature for 1 week. The aqueous phase was neutralized to $\mathrm{pH} 7.0$ through the addition of calcium hydroxide and stored at $-30{ }^{\circ} \mathrm{C}$. Pretreatments were performed at least in triplicate on each biomass, and data obtained from these two methods were compared throughout this study.

Chemical Analysis. Biomass and Fractions Characterization. All analyses were performed in triplicate.

Ash was determined by gravimetry, as the solid remaining after combustion for $6 \mathrm{~h}$ at $575^{\circ} \mathrm{C}$ in a muffle furnace based on the NREL method. ${ }^{24}$

Extractives quantification was carried out using a Soxhlet apparatus according to the NREL method. ${ }^{25}$

Protein content was estimated by measuring the nitrogen content according to the Kjeldahl method. Mineralization was performed using a TECATOR 1015 instrument followed by a titration using a Kjeltec 2300 (Foss). The results were multiplied by 6.25 , the conversion factor which is used for animal feed and other materials. ${ }^{26}$

Total sugar content was determined in aqueous phases (from pretreatment and saccharification), raw biomasses, and pretreated solids. The polysaccharide molecular composition in solids was determined based on the monomer content using a standard two-step acid hydrolysis from Sluiter et al. ${ }^{27}$ Gas chromatography analysis was performed according to the method described in Matsuda et al. ${ }^{23} \mathrm{~A}$ total of $1.5 \mu \mathrm{L}$ of diluted sample as well as the same volume of ribitol (internal standard; $0.1 \%[\mathrm{w} / \mathrm{w}]$ ) were added to Eppendorf tubes and freeze-dried using a centrivap concentrator (Labconco). The solid residue was then dissolved in $100 \mu \mathrm{L}$ of methoxyamine hydrochloride dissolved in pyridine $\left(20 \mathrm{mg} \mathrm{mL}^{-1}\right)$ and incubated at $30{ }^{\circ} \mathrm{C}$ for 90 $\mathrm{min}$ at $1200 \mathrm{rpm}$ in a BioShaker MBR-022UP (Taitec). A total of 50 $\mu \mathrm{L}$ of $\mathrm{N}$-methyl-N-trimethylsilyltrifluoroacetamide (MSTFA) was added as a derivatization agent prior to incubation at $37{ }^{\circ} \mathrm{C}$ for 30 min at $1200 \mathrm{rpm}$ in the same device. Analyses were carried out using a GCMS-2010 (Shimadzu) gas chromatograph equipped with a mass 
Table 1. Chemical Composition of Raw Biomasses

\begin{tabular}{|c|c|c|c|c|c|c|c|}
\hline \multirow{2}{*}{\multicolumn{2}{|c|}{ components $^{a}$}} & \multicolumn{6}{|c|}{ wt $\%$ dry basis } \\
\hline & & TFE & SBP & BEW & JCW & EUW & SCB \\
\hline \multirow[t]{3}{*}{ lignin } & & $20.1 \pm 0.3$ & $9.7 \pm 0.2$ & $21.6 \pm 0.3$ & $33.1 \pm 0.4$ & $28.0 \pm 0.7$ & $24.0 \pm 0.5$ \\
\hline & klason lignin & $15.2 \pm 0.1$ & $2.1 \pm 0.1$ & $19.6 \pm 0.3$ & $32.0 \pm 0.4$ & $16.8 \pm 0.6$ & $18.7 \pm 0.4$ \\
\hline & acid soluble lignin & $4.9 \pm 0.2$ & $7.6 \pm 0.1$ & $2.0 \pm 0.0$ & $1.1 \pm 0.0$ & $11.2 \pm 0.1$ & $5.3 \pm 0.1$ \\
\hline \multicolumn{2}{|c|}{ polysaccharides } & $49.3 \pm 2.0$ & $56.6 \pm 1.6$ & $60.1 \pm 1.2$ & $56.2 \pm 0.9$ & $64.0 \pm 0.9$ & $63.6 \pm 1.6$ \\
\hline & glucan & $31.8 \pm 1.0$ & $28.5 \pm 0.5$ & $41.9 \pm 0.3$ & $40.8 \pm 0.7$ & $46.7 \pm 0.6$ & $42.1 \pm 0.9$ \\
\hline & xylan & $11.8 \pm 0.3$ & $1.1 \pm 0.0$ & $13.9 \pm 0.6$ & $4.5 \pm 0.1$ & $13.2 \pm 0.3$ & $16.4 \pm 0.1$ \\
\hline & mannan & $0.6 \pm 0.0$ & $1.6 \pm 0.1$ & $1.8 \pm 0.2$ & $7.6 \pm 0.1$ & $1.5 \pm 0.0$ & $0.9 \pm 0.0$ \\
\hline & galactan & $1.7 \pm 0.1$ & $6.5 \pm 0.6$ & $1.6 \pm 0.1$ & $2.0 \pm 0.0$ & $1.7 \pm 0.0$ & $1.2 \pm 0.6$ \\
\hline & arabinan & $3.4 \pm 0.3$ & $18.9 \pm 0.4$ & $0.9 \pm 0.0$ & $1.3 \pm 0.0$ & $0.9 \pm 0.0$ & $3.0 \pm 0.0$ \\
\hline \multirow[t]{3}{*}{ extractives } & & $17.7 \pm 1.7$ & $19.7 \pm 0.3$ & $5.2 \pm 0.1$ & $8.6 \pm 0.3$ & $3.8 \pm 0.2$ & $9.7 \pm 0.1$ \\
\hline & water extractives & $13.8 \pm 1.2$ & $16.8 \pm 0.3$ & $4.3 \pm 0.1$ & $3.2 \pm 0.2$ & $2.9 \pm 0.3$ & $7.9 \pm 0.1$ \\
\hline & ethanol extractives & $3.8 \pm 0.5$ & $2.9 \pm 0.1$ & $0.9 \pm 0.0$ & $5.4 \pm 0.1$ & $0.8 \pm 0.0$ & $1.8 \pm 0.0$ \\
\hline protein & & $7.9 \pm 0.5$ & $9.4 \pm 0.2$ & $0.6 \pm 0.0$ & $2.1 \pm 0.0$ & $0.6 \pm 0.1$ & $0.9 \pm 0.1$ \\
\hline ash & & $11.5 \pm 0.4$ & $5.7 \pm 0.3$ & $0.4 \pm 0.0$ & $2.6 \pm 0.2$ & $0.6 \pm 0.0$ & $1.6 \pm 0.0$ \\
\hline total $^{b}$ & & $98.6 \pm 4.4$ & $91.7 \pm 2.4$ & $87.3 \pm 1.6$ & $100.5 \pm 1.8$ & $96.4 \pm 1.8$ & $98.9 \pm 2.2$ \\
\hline
\end{tabular}

detector (QP2010Plus, Shimadzu) and an autosampler (AOC-20i, Shimadzu).

The compounds were separated using a capillary column, CP-Sil 8CB low bleed/MS $(30 \mathrm{~m} \times 0.25 \mathrm{~mm}$ ID, $0.25 \mu \mathrm{m}$ film thickness; Agilent Inc., Palo Alto, CA, USA). Helium was used as a carrier gas at a flow rate of $1.6 \mathrm{~mL} \mathrm{~min}^{-1}$. The column temperature was held at 80 ${ }^{\circ} \mathrm{C}$ for $2 \mathrm{~min}$ followed by a linear increase by $15{ }^{\circ} \mathrm{C} \min ^{-1}$ to $330{ }^{\circ} \mathrm{C}$ and maintained at this temperature for $1 \mathrm{~min}$. Samples were injected in split mode (split ratio: 100), and the injection chamber was set at $230{ }^{\circ} \mathrm{C}$. The interface and the ion source temperatures were 250 and $200{ }^{\circ} \mathrm{C}$, respectively. Ions were generated using a $70 \mathrm{~V}$ electron impact, and ion fragments were detected in the selected ion monitoring mode. D- $(+)$-glucose, D- $(+)$-xylose, D- $(+)$-mannose, and ribitol were purchased at Nacalai Tesque (Kyoto, Japan). L(-)-arabinose was purchased at Sigma-Aldrich (Saint Louis, USA). The anhydro corrections ( 0.88 for pentoses and 0.90 for hexoses) were applied to the monomeric sugar concentrations in order to obtain the concentration of the corresponding polymeric sugars. The recovery of carbohydrates from raw material was calculated as follows:

$$
\frac{\mathrm{g} \text { recovered in solids }}{\mathrm{g} \text { of initial compound }} \times 100
$$

Klason lignin content (acid-insoluble lignin: AIL) and lignin purity were determined according to an NREL protocol. ${ }^{27}$ In the first step, 3 $\mathrm{mL}$ of $72 \%[\mathrm{w} / \mathrm{w}]$ sulfuric acid was added to $300 \mathrm{mg}$ of dried matter and incubated at $30{ }^{\circ} \mathrm{C}$ for $1 \mathrm{~h}$. In the second step, the reaction mixture was diluted to $4 \%[\mathrm{w} / \mathrm{w}]$ with deionized water and autoclaved at $121{ }^{\circ} \mathrm{C}$ for $1 \mathrm{~h}$. The hydrolysate was then neutralized by the addition of powdered calcium hydroxide. The acid-soluble lignin (ASL) was measured by spectrophotometry using a UV-1800 Shimadzu spectrophotometer at $205 \mathrm{~nm}$. This wavelength allows minimizing interferences from degradation products. ${ }^{28}$ The yields of soluble (ASL), insoluble (Klason, AIL), and total lignin (ASL + AIL) recovered by precipitation were calculated as follows:

$$
\frac{\text { g recovered lignin }}{\mathrm{g} \text { of initial lignin }} \times 100
$$

Acetic acid (HAc), formic acid, 5-hydroxymethylfurfural (5-HMF), and 2 -furfural, in the aqueous and butanol fractions, were analyzed by gas chromatography according to Sakamoto et al. ${ }^{29}$ using a (GC2010, Shimadzu) gas chromatograph equipped with a mass detector (QP2010Plus, Shimadzu) and an autosampler (AOC-20i, Shimadzu).

Separation of acids (formic and acetic) was carried out on a DBFFAP column $(60 \mathrm{~m} \times 0.25 \mathrm{~mm}$ ID, $0.5 \mu \mathrm{m}$ film thickness; Agilent, Palo Alto, CA, USA). Helium was used as the carrier gas at a flow rate of $0.94 \mathrm{~mL} \mathrm{~min}^{-1}$. The column temperature was held at $100{ }^{\circ} \mathrm{C}$ for 5 min followed by a linear increase by $10{ }^{\circ} \mathrm{C} \mathrm{min}^{-1}$ to $230{ }^{\circ} \mathrm{C}$ and maintained at this temperature for $6 \mathrm{~min}$.

Separation of furan compounds (5-HMF and 2-furfural) was carried out on a CP-Sil 8-CB low bleed/MS column $(30 \mathrm{~m} \times 0.25$ $\mathrm{mm}$ ID, $0.25 \mu \mathrm{m}$ film thickness; Agilent Inc., Palo Alto, CA, USA). Helium was used as a carrier gas at a flow rate of $1.69 \mathrm{~mL} \mathrm{~min}^{-1}$. The column temperature was held at $50{ }^{\circ} \mathrm{C}$ for $1 \mathrm{~min}$ followed by a linear increase by $20{ }^{\circ} \mathrm{C} \min ^{-1}$ to $280{ }^{\circ} \mathrm{C}$ and maintained at this temperature for $1 \mathrm{~min}$.

Samples were injected in split mode (split ratio: 10), and the injection chamber was set at $250^{\circ} \mathrm{C}$. The interface and the ion source temperatures were 250 and $230{ }^{\circ} \mathrm{C}$, respectively. Ions were generated using a $70 \mathrm{~V}$ electron impact, and ion fragments were detected in the selected ion monitoring mode. 5-HMF, furfural, and acetic acid standards were purchased at Nacalai Tesque (Kyoto, JAPAN); formic acid was purchased at Wako.

Scanning Electron Microscopy. The untreated biomass and solid samples from pretreatment surfaces were morphologically analyzed using scanning electron microscopy (SEM). Samples were mounted on aluminum stubs with carbon tape and sputter coated with palladium using a JEOL JFC-1600 auto fine coater. Images were acquired on a JEOL JSM-7500F field emission (FE) scanning electron microscope at 5.0 and $7.0 \mathrm{kV}$ beam accelerating voltage at a magnification ranging from 5000 to 30000 .

2D HSQC NMR (Two Dimensional Heteronuclear Single Quantum Correlation Nuclear Magnetic Resonance). A total of $50 \mathrm{mg}$ of lignin was dissolved in $750 \mu \mathrm{L}$ of DMSO-d 6 . NMR analysis was conducted using a Bruker AVIIIHD (400 MHz). The spectra were obtained at $25{ }^{\circ} \mathrm{C}$ on a Bruker AVIIIHD 400 NMR spectrometer, observing ${ }^{1} \mathrm{H}$ at $400 \mathrm{MHz}$ and ${ }^{13} \mathrm{C}$ at $100 \mathrm{MHz}$. Chemical shifts were expressed as $\delta \mathrm{ppm}$, using the resonances of DMSO $(\delta \mathrm{C} / \delta \mathrm{H} 39.52 / 2.50)$ as an internal reference. ${ }^{6}$

Gel Permeation Chromatography (GPC). A total of $3 \mathrm{mg}$ of lignin samples was dissolved in $1 \mathrm{~mL}$ of DMF, filtered with $0.45 \mu \mathrm{m}$ filters and injected on a Waters 2690 separations module equipped with a TSKgel G3000PWXL column $200 \AA$ ( 7 and $6 \mu \mathrm{m}$ particle size) and a UV detector (Waters 996 photo diode array detector) operating at 280 $\mathrm{nm}$ at $30{ }^{\circ} \mathrm{C}$. The eluent was $\mathrm{NaH}_{2} \mathrm{PO}_{4} \cdot \mathrm{H}_{2} \mathrm{O} / \mathrm{NaOH}$ buffer $(\mathrm{pH}$ 12)

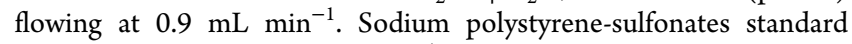
samples were used for calibration $(210 \mathrm{Da}, 4.3 \mathrm{kDa}, 6.8 \mathrm{kDa}, 10 \mathrm{kDa}$, $17 \mathrm{kDa}$, and $32 \mathrm{kDa}){ }^{6}$

Enzymatic Saccharification. Enzymatic hydrolysis was performed in a buffered fermentation medium at $\mathrm{pH} 5$ (constituted by sodium citrate/citric acid, tetracycline, cycloheximide). Dried cellulosic residue after pretreatment was added in the medium to reach a 
concentration of $100 \mathrm{mg} \mathrm{mL}$. After adding Cellic CTec2 (Novozyme) at a load of $6.6 \mathrm{FPU} \mathrm{g}^{-1}$, the reaction mixture was incubated at $50{ }^{\circ} \mathrm{C}$ for $72 \mathrm{~h}$ by stirring at $120 \mathrm{rpm}$ in a PPS-25W Chemi Station (EYELA). ${ }^{30}$

All analyses were performed in triplicate.

\section{RESULTS AND DISCUSSION}

Comparison of Raw Biomasses Chemical Composition. Table 1 provides the composition of major constituents on a dry matter basis. Eucalyptus wood (EUW) contains the highest amount of cellulose (46.7\%) and the second-highest lignin content $(28.0 \%)$. However, the Klason lignin (AIL) is low compared to the literature balue, while, in contrast, the acid-soluble lignin (ASL) is high. ${ }^{31}$ Sugar cane bagasse (SCB) contains $16.4 \%$ xylan and is the most suitable biomass for the coproduction of xylose-derived products. The composition is similar to data found in the literature. ${ }^{32}$ Beech wood (BEW) composition is in agreement with the conclusion of Simon et al. ${ }^{33}$ The total quantity of lignin found in the Japanese cedar wood (JCW) sample was $33.1 \%$, the highest among the materials considered. Japanese cedar also had the highest Klason lignin (AIL) content (32\%) corroborated by those reported by Sagehashi et al. ${ }^{34}$ Sugar beet pulp (SBP) is expected to be less recalcitrant to pretreatment since it is the least lignified material. The data are quite similar to the literature. ${ }^{35}$ Tall fescue (TFE) contains the lowest amount of polysaccharides $(49.3 \%)$; the measurement corresponds with the findings of Njoku et $\mathrm{al}^{36}$

Increase of Lignin Removal from Various Lignocellulosic Biomasses by BUTP Compared to DAP. This study compares the effects of both dilute acid pretreatment (DAP) " $\mathrm{H}_{2} \mathrm{SO}_{4} 1 \%[\mathrm{v} / \mathrm{v}]$ " - and butanol pretreatment (BUTP) - " $1: 3$ $(\mathrm{v} / \mathrm{v}) n$-butanol $/ \mathrm{H}_{2} \mathrm{SO}_{4} 1 \%[\mathrm{v} / \mathrm{v}]$ " - on the fractionation of six biomasses.

The yields of nonhydrolyzed cellulose recovered ( $\mathrm{g}$ of recovered cellulose/g of initial cellulose) are displayed in Figure 1A. More than $30 \%$ of the cellulose in the SBP was hydrolyzed during both the DAP and the BUTP, probably due to the low lignin content. The hydrolysis of cellulose is not significantly affected by butanol addition of DAP and BUTP,

a
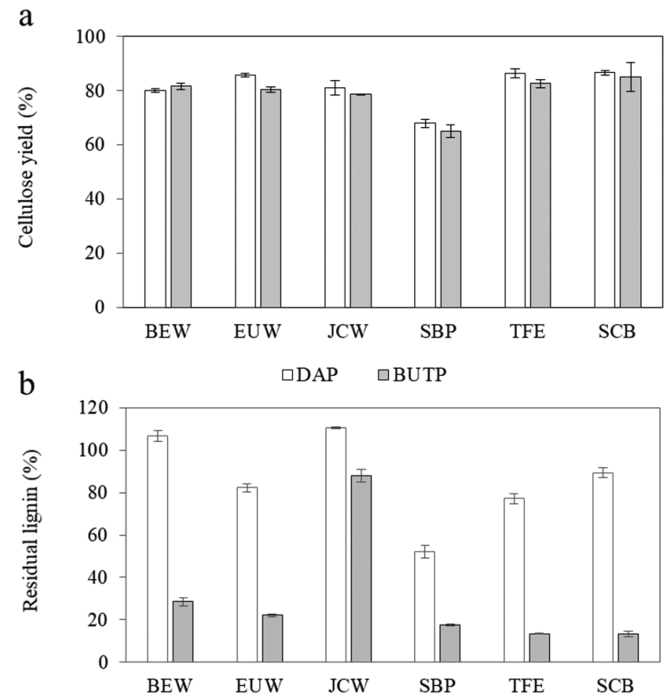

Figure 1. Yield of recovered (a) cellulose and (b) lignin from DAP and BUTP. Residual lignin percentages higher than $100 \%$ are due to overestimation of pseudolignin. regardless of material. Figure $1 \mathrm{~B}$ shows the percentage of remaining lignin in the cellulosic residue ( $\mathrm{g}$ residual/g initial). BUTP significantly improves delignification compared to DAP except for JCW and SBP. Only $12 \%$ of the JCW lignin could be removed, and significant delignification from SBP occurred even without the use of butanol. BUTP resulted in $87 \%$ delignification for TFE and SCB, up from $23 \%$ for TFE and $11 \%$ for SCB after DAP. BEW and JCW experienced significantly less delignification, as was expected, to be in accordance with their high Klason lignin content, considered to be responsible for biomass recalcitrance. ${ }^{21}$ In addition, the Klason lignin content is overestimated after DAP most likely due to the formation of a material from acid-catalyzed dehydration of cellulose and hemicelluloses. This material, referred to in the literature as "pseudo-lignin," is acid insoluble and is accounted for gravimetrically in the solid residue and considered as lignin in the Klason method. The phenomenon was previously reported by several researchers and investigated by $\mathrm{Hu}$ et al. ${ }^{3}$

Effect of Pretreatment on Biomass Surface Morphology. The impact of pretreatment on the surface of nonwoody biomass (Figure 2) and woody biomass (Figure 3) samples was characterized using scanning electron microscopy (SEM).

The surface of raw sugar cane bagasse (Figure 2A.1) appeared smooth and inaccessible. The effect of DAP on SCB is clearly revealed in Figure 2B.1, in which spherical droplets are observed on the surface. By contrast, pretreated SCB by BUTP (Figure 2C.1) is free from droplets. The untreated tall fescue surface (Figure 2A.2) was similar to SCB. The solid after DAP (Figure 2B.2) was sprinkled with homologous small droplets. The BUTP left a pretreated TFE (Figure 2C.2) free from droplets which was more destabilized. Dissociated fibers were observed and suggested to be cellulose microfibrils. Concerning the structure of raw sugar beet pulp (Figure 2A.3), the surface was irregular and did not present any fiber-like structures. By contrast, dissociated fibers appeared after both DAP (Figure 2B.3) and BUTP (Figure 2C.3). Pretreated solids from BUTP and DAP are very similar in appearance and support the fact that BUTP introduces a minor improvement to DAP performed on SBP. The hypothesis proposed by Selig et al. $^{38}$ concerning the droplets suggests that the heat applied during pretreatment is sufficient to melt lignin, which can then migrate through the matrix, ultimately coalescing as spherical droplets on the surface. They also demonstrated that the enzymatic saccharification rate is decreased by this phenomenon. In addition, a study performed under very similar conditions to those of the present study $\left(180^{\circ} \mathrm{C}, \mathrm{H}_{2} \mathrm{SO}_{4} 0.1 \mathrm{M}\right.$ for $40 \mathrm{~min})^{37}$ revealed that pseudolignin formation leads to deposition of homologous droplet structures on the solid surface. Figure 2C.1 and C.2 suggest that butanol efficiently prevents the formation of lignin or pseudolignin deposition on the surface of biomass samples. In addition, the structure of the sample after BUTP is notably more open, and its fiber structure is more apparent. Droplets were not observed on any SBP samples, which may be explained by the small initial amount of lignin.

The pretreated Japanese cedar recovered after DAP (Figure 3B.4) and BUTP (Figure 3C.4) were very similar. Droplets were observed on sample surfaces after both pretreatments while the surface of the raw material was free of it (Figure 3A.4), reflecting a low delignification yield. However, the deposition appeared to be less spherical in Figure 3C.4, probably due to a partial solubilization in the butanol phase. 


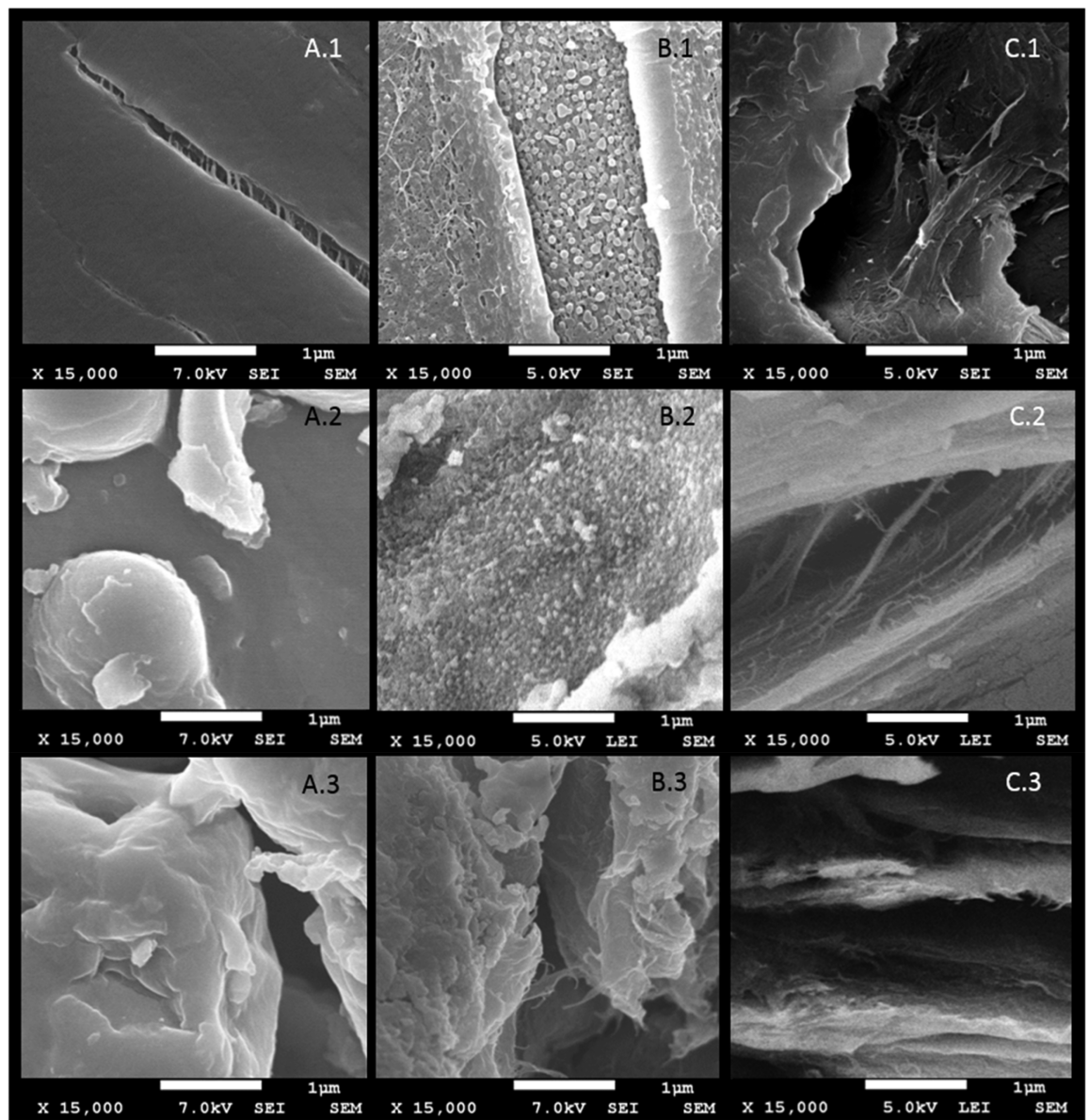

Figure 2. SEM pictures of (A) raw material; (B) DAP pretreated solid; (C) BUTP solid of (1) SCB, (2) TFE, (3) SBP.

Concerning eucalyptus, the pretreated solid by DAP (Figure 3B.5) showed the widest area covered by droplets. This is probably due to the high amount of ASL, which led to the plate-out of the surface by the lignin recondensation, as described by Kärcher et al. ${ }^{39}$ The eucalyptus surfaces examined after the BUTP (Figure 3C.5) were free of droplets and revealed internal fiber structure not visible on the raw biomass (Figure 3A.5). Surprisingly, the raw beech sample (Figure 3A.6) presented fiber structures prior to pretreatment and seems to be less resistant to mechanical treatments, possibly due to the biomass comminution performed prior to composition and surface analyses. Dissociated fibers were also observed in pretreated solid samples, as shown in Figure 3C.6. Less lignin deposition was observed on the surface after DAP (Figure 3B.6) than on eucalyptus, correlated by the lower content of ASL.

Lignin Recovery and Purity. The composition of recovered lignins indicates that the purity assessed by the Klason method is high, with rates going from 93\% for Japanese cedar to $96.4 \%$ for eucalyptus (Table S1). However, significant contamination by proteins was observed in the case of TFE and SBP due to the high initial protein content in the raw material. In addition, acid-resistant proteins can probably increase the amount of Klason lignin. ${ }^{40}$ The yields of total lignin recovered by precipitation are presented in Figure 4. AIL content in SBP after pretreatment is considerably overestimated (AIL yield corresponding to 199\%; data not shown). It can be explained by a coprecipitation of protein from the raw biomass and formation of resistant material from polysaccharides. $^{6}$ The total lignin yield from JCW is low (20\%) and probably overestimated by pseudolignin since this yield is higher than the estimated delignification (12\%) based on the remaining lignin in the pretreated solid. JCW was particularly resistant to BUTP, affecting therefore the recovery. Kawamata et al. performed similar treatment on JCW at $200{ }^{\circ} \mathrm{C}$ using a silica-iron redox catalyst to improve lignin fragmentation by oxidation and obtained about a $50 \%$ removal of lignin. ${ }^{41}$ The method was more efficient for recovering lignin from every other biomass. More than $60 \%$ was achieved, up to $66 \%$, for SCB.

Lignin Structure Analysis by 2D-HSQC NMR and GPC. 2D-HSQC NMR was performed on lignin recovered from the six different biomasses. Three different regions were investigated: the aromatic region $\left(\delta^{13} \mathrm{C} / \delta^{1} \mathrm{H} 100-150 / 6.0-\right.$ $8.0)$, the oxygenated aliphatic side chain region $\left(\delta^{13} \mathrm{C} / \delta^{1} \mathrm{H} 1 \mathrm{H}\right.$ 50-90/3.0-5.0), and the carbohydrates region $\left(\delta^{13} \mathrm{C} / \delta^{1} \mathrm{H}\right.$ 90-150/4.0-5.5). Peak assignments to $\delta^{13} \mathrm{C} / \delta^{1} \mathrm{H}$ cross-signals were compared with the literature and summarized in Table 2. , $^{-42-51}$ The strongest signal in the side-chain region of every biomass was attributed to methoxyl groups $\left(-\mathrm{OCH}_{3}\right)(55.4-$ $56.4 / 3.72-3.76 \mathrm{ppm}){ }^{6,42-51}$ The guaiacyl $(\mathrm{G})$ ring $\mathrm{C}_{5}-\mathrm{H}_{5}$ cross-signal in the aromatic region at $114.3-115.6 / 6.67-6.72$ ppm attests to the $G$ unit presence in every biomass. ${ }^{42,46,49}$ It is worth noting that no signal arising from cellulose was found, suggesting low contamination by residual cellulose. Regarding hardwoods (BEW and EUW), the presence of a syringyl unit (S) is confirmed at $104.2 / 6.64 \mathrm{ppm}$ corresponding to a $\mathrm{C}_{2,6}-$ $\mathrm{H}_{2,6}$ signal. ${ }^{6}$ Additional signals corresponding to an oxidized 


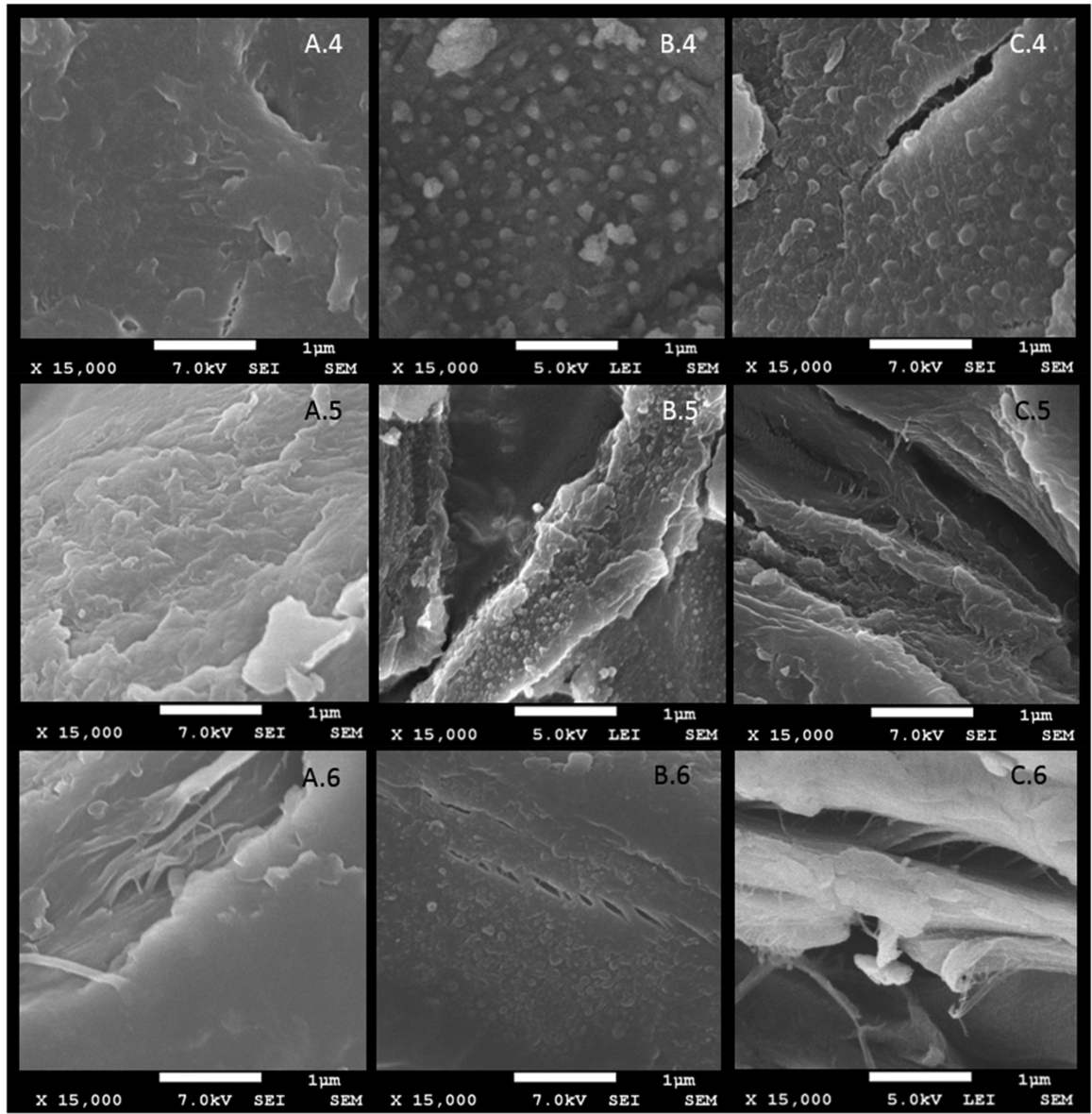

Figure 3. SEM pictures of (A) raw material; (B) DAP solid; (C) BUTP solid of (4) JCW, (5) EUW, (6) BEW.

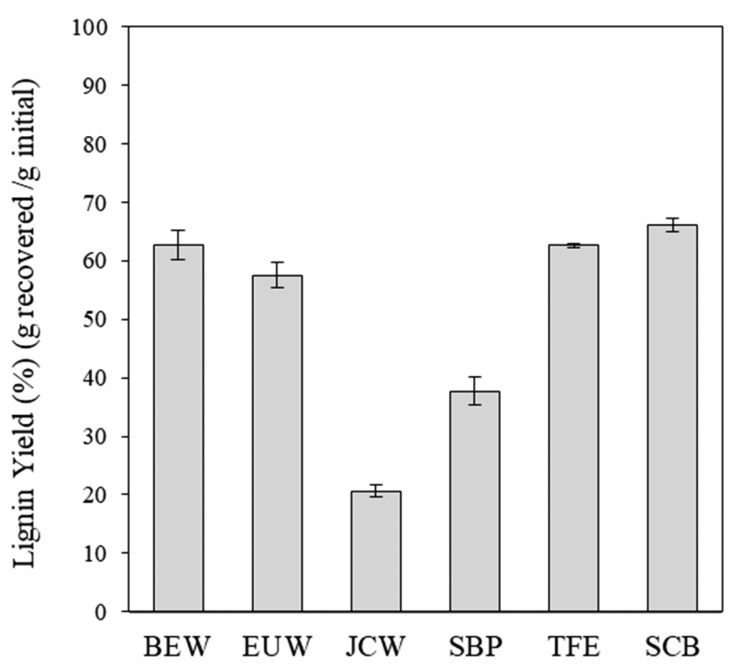

Figure 4. Yield (\%) of recovered total lignin (ASL+AIL).

guaiacyl unit $\left(G^{\prime}\right)$ at $110.8-11.8 / 7.48 \mathrm{ppm}$ and oxidized syringyl units at $107.4 / 7.22$ ppm highlight the occurrence of oxidation and therefore lignin degradation. ${ }^{42,47,50}$ However, the intensity of the $\beta$-O- $4^{\prime}$ substructure signal suggests an ether bond conservation. Contamination is suggested by several occurrences of hemicellulosic carbohydrate signals. ${ }^{6,45}$ On the contrary, softwood (JCW) lignin shows low contamination and is free of oxidized units. Several $\beta$-O- $4^{\prime}$ substructure signals indicate conservation as well. $\mathrm{C}_{\beta}-\mathrm{H}_{\beta}$ in cinnamaldehyde end groups is found at $126.8 / 6.77$ ppm. $^{43}$ As expected, ferulate
(FA) and $p$-coumarate (PCA) are identified only in nonwoody biomass (TFE, SCB, SBP). ${ }^{6,42,43,48}$ An oxidized syringyl unit signal is present at $106.3-106.7 / 7.20-7.21 \mathrm{ppm}$ in both TFE and SCB lignins. ${ }^{50}$ Acetylated xylan and mannan at respectively $101.3 / 4.75$ and $98.9 / 4.58 \mathrm{ppm}$ are found only in TFE, indicating contamination by hemicelluloses. ${ }^{45}$ SCB lignin is the only nonwoody biomass exempt from a $p$-hydroxyphenyl unit $(\mathrm{H})$ and appears free from carbohydrate contamination. $^{42,49} \beta$-O- $4^{\prime}$ linkage intensity is weak at $59.9 / 3.69$ and $59.9 / 3.38$ ppm for TFE and SCB respectively and absent from SBP. ${ }^{50}$ In addition, SBP presents only two signals related to aromatic groups and no linkage substructure. $\alpha$-L-Araf and (1 $\rightarrow 4)-\beta$-D-Galp, side chains commonly found in SBP pectin, are found at 107.5/4.67 and 98.8/4.61, respectively. ${ }^{45}$ All in all, it suggests a low content of lignin and several contaminations more likely from pectin (galacturonic acid) derivatives. ${ }^{52}$ Contamination presence is supported by a nonassigned peak according to commonly found chemical shifts from lignin (Figure S1.18).

Molecular weights of extracted lignins were determined using GPC. Chromatograms are presented in Figure 5, and molecular weights are compiled in Table 3. High molecular weight lignins (peak 1) correspond to 60 to $80 \%$ of the weight distribution, whereas peaks $2(1150 \mathrm{Da})$ and $3(360-380 \mathrm{Da})$ account for 10 to $20 \%$ each for every biomass source. It appears that hardwoods (BEW and EUW) underwent the treatment similarly, resulting in higher molecular weight fragments $(4250 \mathrm{Da})$ as main products correlated by $\beta$-O $-4^{\prime}$ substructure conservation. That could reflect a similar initial 
Table 2. Coordinates $\left(\delta^{13} \mathrm{C} / \delta{ }^{1} \mathrm{H}\right)$ and Their Respective Assignments in HSQC NMR Spectra of Precipitated Lignin

\begin{tabular}{|c|c|c|c|c|c|c|}
\hline \multirow[b]{2}{*}{ assignments $^{a}$} & \multicolumn{6}{|c|}{$\delta{ }^{13} \mathrm{C} / \delta{ }^{1} \mathrm{H}(\mathrm{ppm})$} \\
\hline & BEW & EUW & $\mathrm{JCW}$ & TFE & SBP & SCB \\
\hline \multicolumn{7}{|c|}{ aromatic region } \\
\hline $\mathrm{C}_{2}-\mathrm{H}_{2}$ ferulic acid units (FA) & & & & $144.5 / 7.57$ & & $144.3 / 7.52$ \\
\hline $\mathrm{C}_{\alpha}-\mathrm{H}_{\alpha} p$-coumarate (PCA and FA) & & & & & & $144.5 / 7.40$ \\
\hline $\mathrm{C}_{2,6}-\mathrm{H}_{2,6} p$-hydroxybenzoate (PB) & & & $131.6 / 7.61$ & $130.1 / 7.55$ & & \\
\hline $\mathrm{C}_{2,6}-\mathrm{H}_{2,6} p$-coumarate $(\mathrm{PCA})$ & & & & & & $130.0 / 7.45$ \\
\hline $\mathrm{C}_{2,6}-\mathrm{H}_{2,6} p$-hydroxyphenyle units $(\mathrm{H})$ & & & $128.5 / 7.23$ & $128.0 / 7.22$ & & \\
\hline $\mathrm{C}_{\beta}-\mathrm{H}_{\beta}$ in cinnamaldehyde end groups & & & $126.8 / 6.77$ & & & \\
\hline $\mathrm{C}_{6}-\mathrm{H}_{6}$ ferulate $(\mathrm{FA})$ & & & & $122.8 / 7.12$ & $122.3 / 7.11$ & $122.7 / 7.10$ \\
\hline $\mathrm{C}_{6}-\mathrm{H}_{6}$ guaiacyl units $(\mathrm{G})$ & $119.7 / 6.77$ & $119.6 / 6.77$ & $118.8 / 6.65$ & $119.3 / 6.72$ & & \\
\hline $\mathrm{C}_{5}-\mathrm{H}_{5}$ guaiacyl units ( $\mathrm{G}$ and $\mathrm{PCA}$ ) & & & & $115.3 / 6.79$ & $114.8 / 6.79$ & $115.4 / 6.77$ \\
\hline $\mathrm{C}_{5}-\mathrm{H}_{5}$ guaiacyl units $(\mathrm{G})$ & $115.6 / 6.72$ & $115.6 / 6.71$ & $114.7 / 6.65$ & $115.2 / 6.7$ & $114.3 / 6.68$ & $114.8 / 6.67$ \\
\hline $\mathrm{C}_{2}-\mathrm{H}_{2}$ oxidized guaiacyl units $\left(G^{\prime}\right)$ & $111.8 / 7.49$ & $110.8 / 7.48$ & & & & \\
\hline $\mathrm{C}_{2}-\mathrm{H}_{2}$ ferulate $(\mathrm{FA})$ & & & & $111.0 / 7.33$ & $110.5 / 7.32$ & $110.7 / 7.32$ \\
\hline $\mathrm{C}_{2}-\mathrm{H}_{2}$ guaiacyl units $(\mathrm{G})$ & $111.7 / 6.93$ & $111.8 / 6.94$ & $110.7 / 6.94$ & & & \\
\hline $\mathrm{C}_{2,6}-\mathrm{H}_{2,6}$ in $\alpha$-oxidized syringyl units $\left(\mathrm{S}^{\prime}\right)$ & $107.4 / 7.22$ & $107.3 / 7.22$ & & $106.7 / 7.21$ & & $106.2 / 7.31 \quad 106.3 / 7.20$ \\
\hline $\mathrm{C}_{2,6}-\mathrm{H}_{2,6}$ syringyl units $(\mathrm{S})$ & $104.2 / 6.64$ & $104.2 / 6.62$ & & $103.5 / 6.67$ & & $103.6 / 6.63$ \\
\hline \multicolumn{7}{|c|}{ carbohydrate region } \\
\hline$\alpha$-L-Araf & & & & & $107.5 / 4.67$ & \\
\hline$\beta$-L-Araf & $104.5 / 5.10$ & $102.4 / 5.35$ & & & & \\
\hline$(1 \rightarrow 3)-G l c p$ & $103.8 / 4.58$ & $102.4 / 3.69$ & $103.2 / 4.56$ & $103.3 / 4.60$ & & \\
\hline 3-O-Ac-Man $p$ & $99.7 / 4.71$ & $99.9 / 4.71$ & & $101.3 / 4.75$ & & \\
\hline $2-\mathrm{O}-\mathrm{Ac}-\beta$-D-Xylp & $99.4 / 4.58$ & $99.4 / 4.59$ & & $98.9 / 4.58$ & & \\
\hline$(1 \rightarrow 4)-\beta-\mathrm{D}-\mathrm{Gal} p$ & & & & & $98.8 / 4.61$ & \\
\hline \multicolumn{7}{|c|}{ side chain region } \\
\hline $\mathrm{C}_{\beta}-\mathrm{H}_{\beta}$ in $\beta$-O-4' substruct. linked to $\mathrm{G}$ & $87.3 / 4.33$ & & $83.1 / 4.30$ & & & \\
\hline $\mathrm{C}_{\gamma}-\mathrm{H}_{\gamma} \gamma$-hydroxylated $\beta$-O- $4^{\prime}$ subst. & $60.3 / 3.39$ & $60.6 / 3.39$ & $59.9 / 3.39$ & & & $59.9 / 3.38$ \\
\hline $\mathrm{C}_{\gamma}-\mathrm{H}_{\gamma} \beta-\mathrm{O}-4^{\prime}$ substruct. & $60.3 / 3.63$ & $60.3 / 3.64$ & & $59.9 / 3.69$ & & \\
\hline $\mathrm{C}_{\alpha}-\mathrm{H}_{\alpha} \beta-\mathrm{O}-4^{\prime}$ substruct. & $72.2 / 4.88$ & $72.4 / 4.88$ & $71.0 / 4.75$ & & & \\
\hline $\mathrm{O}-\mathrm{CH}_{3}$ (methoxyl) & $56.3 / 3.74$ & $56.4 / 3.75$ & $55.4 / 3.74$ & $55.6 / 3.76$ & $55.0 / 3.75$ & $55.5 / 3.72$ \\
\hline
\end{tabular}
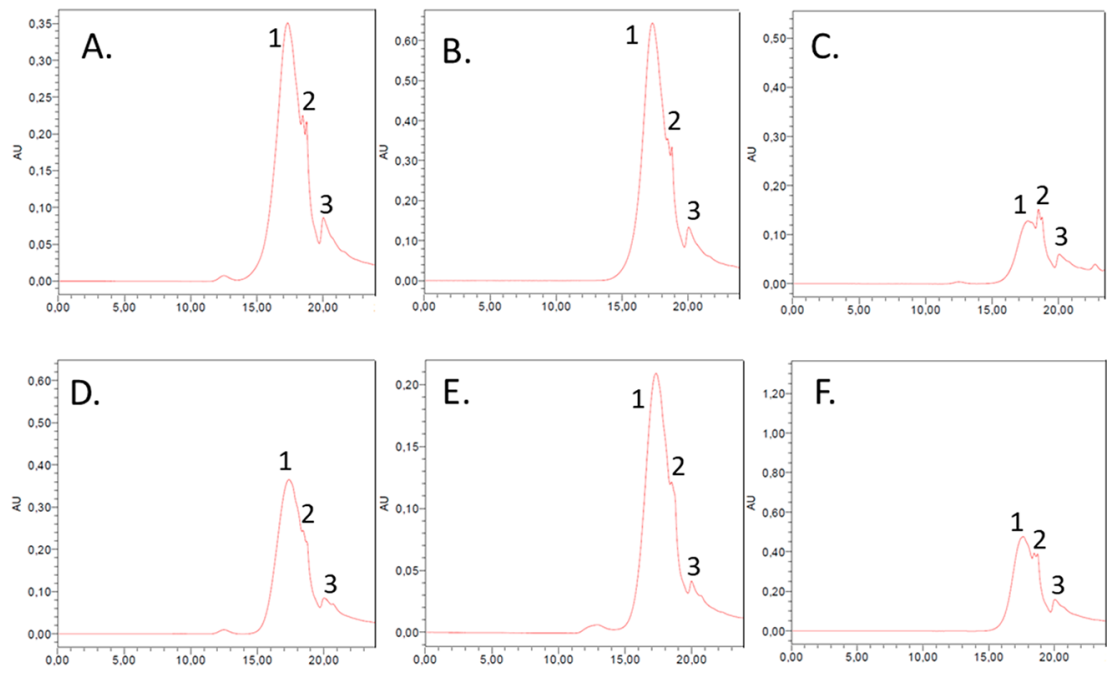

Figure 5. Gel permeation chromatograms of lignin recovered after BUTP from BEW (A), EUW (B), JCW (C), TFE (D), SBP (E), and SCB (F).

structure for both hardwoods. Lignin from JCW was cleaved to lower mass fragments $(3000 \mathrm{Da})$ in accord with the results from Kawamata et al. using an $n$-butanol/water mixture at similar temperatures. ${ }^{42}$ That could suggest a selective extraction of short fragments. Nevertheless, it is worth noting that the presence of higher molecular weight lignins in the butanol phase from other biomass treatments tends to suggest an extraction of a wider range of $M_{\mathrm{w}}$ compounds.
In addition, considering the low extraction yield, the presence of relatively low $M_{\mathrm{w}}$ lignins could arise from the high recalcitrance of softwood to this kind of treatment. Overall, mass fragments from SCB lignin as low as $60 \%$ were distributed around $3150 \mathrm{Da}$. A total of $17 \%$ and $23 \%$ of the weight distribution account for 1150 and $370 \mathrm{Da}$, respectively. The distribution is similar to that of JCW. However, SCB lignin was produced in higher yield than JCW. A higher S/G 
Table 3. Molecular Weight $\left(M_{\mathrm{W}}\right)^{a}$ of Lignin

$\begin{array}{cccc}\text { biomass } & \text { peak } 1 & \text { peak } 2 & \text { peak 3 } \\ \text { BEW } & 4250 & 1150 & 370 \\ \text { EUW } & 4250 & 1150 & 360 \\ \text { JCW } & 3000 & 1150 & 360 \\ \text { TFE } & 3900 & 1150 & 380 \\ \text { SBP } & 4250 & 1300 & 380 \\ \text { SCB } & 3150 & 1150 & 370\end{array}$

${ }^{a}$ Results expressed as Dalton (Da).

ratio, i.e., higher $\mathrm{S}$ unit proportion and labile $\beta$-O- $4^{\prime}$ bonds, facilitates lignin cleavages and therefore delignification efficiency, which is consistent with the HSQC NMR results. ${ }^{53}$ In addition, extended fragmentation is supported by the low intensity signal from $\beta$-O- $4^{\prime}$ substructures in HSQC NMR spectra. According to $\mathrm{Li}$ et al., breaking down $\beta$-O- $4^{\prime}$ linkages by organosolv pretreatment decreases the average molecular weight. ${ }^{54}$ Intermediate size fragments $(70 \%$ around $3900 \mathrm{Da})$ were produced from TFE, indicating a lower fragmentation than SCB and native linkages less susceptible to be cleaved by BUTP. Lignin from SBP is constituted of $74 \%$ high MW molecules (4250), probably including impurities such as pseudolignin and protein fragments as discussed previously. ${ }^{6}$

Composition of Liquid Phases (Aqueous and Butanol). The analysis of the liquid fractions is of importance to ascertain the presence of inhibitors and the amount of monomeric sugars hydrolyzed from hemicelluloses and cellulose available for further fermentation. Since monosaccharides were present in the butanol phase only in trace concentrations, the discussion about these compounds is limited to their presence in the aqueous phase. GC-MS analyses allowed quantification of the following organic compounds: acetic acid (HAc), formic acid, 2-furfural, and 5-hydroxymethylfurfural (5-HMF). It did not highlight phenolic compounds from lignin in the aqueous phase (Figure S2).

Monosaccharides. A major part of the hemicellulose fraction has been hydrolyzed into monomeric sugars recovered from the aqueous phase. Hydrolysis yields and recoveries calculated for xylose and glucose are compiled in Table 4. BUTP does not significantly improve xylan hydrolysis except in the case of SCB, for which $12 \%$ of the initial biomass was converted into monomeric xylose, increasing the conversion of xylan to xylose from $55 \%$ to $73 \%$. The valorization of SCB appears, therefore, to be more effective when using BUTP.

In terms of glucose recovery, the BUTP seems to hydrolyze slightly more of the raw material than DAP. TFE and SBP appear to be more sensitive to hydrolysis than other biomasses. When the BUTP is performed, glucose recovery increases by between $1.9 \%$ for EUW and $4.3 \%$ for SBP in accordance with the cellulose recovery in the solid.

Presence and Distribution of Organic Compounds in the Aqueous and Butanol Phases. Other organic compounds were formed or released from the lignocellulosic biomass during hydrolysis. Deacetylation of hemicelluloses during pretreatments led to accumulation of $\mathrm{HAc}$ in the liquid phases. In BUTP, HAc is soluble in both the aqueous and the butanol phase. Solubilization in the butanol phase reduced the amount in the aqueous phase obtained from BUTP compared to the DAP (Figure S2.A). In general, the total amount of HAc in the liquid phases of the BUTP did not exceed the amount in the hydrolysate from DAP, suggesting that BUTP did not increase deacetylation except for SCB. Unlike HAc, total formic acid production was increased by BUTP relative to DAP (Figure S2.B), except in the case of JCW, suggesting more degradation from 2-furfural and 5-HMF. A significant proportion of formic acid was extracted in the butanol phase, which tends to reduce the concentration of formic acid in the aqueous phase relative to its concentration in the DAP hydrolysate. In terms of furan derivatives, 2-furfural (Figure S2.C) has shown a greater affinity for the butanol phase. The amount in the aqueous phase was considerably lower after BUTP than after DAP, especially for woods (JCW, 85\% less; EUW, $80 \%$ less). JCW yielded small quantities of furfural owing to a low amount of pentose in hemicellulose. The distribution of 5-HMF (Figure S2.D), suggests that it was produced in a greater amount during BUTP, arising from extensive degradation of hexoses. Concerning the distribution in TFE and SBP cases, 5-HMF was more concentrated in the butanol phase than in the aqueous phase, revealing a different distribution when the concentration was higher.

Enhancement of Enzymatic Saccharification of Pretreated Solids. Saccharification was performed on pretreated

Table 4. Yield and Recovery of Xylose and Glucose in the aqueous phase

\begin{tabular}{|c|c|c|c|c|c|}
\hline \multirow[b]{3}{*}{ biomass } & \multirow[b]{3}{*}{ pretreatment } & \multicolumn{4}{|c|}{ wt $\%$ dry basis } \\
\hline & & \multicolumn{2}{|c|}{ xylose } & \multicolumn{2}{|c|}{ glucose } \\
\hline & & yield $^{a}(\%)$ & recovery $^{b}(\%)$ & yield $^{a}(\%)$ & recovery $^{b}(\%)$ \\
\hline \multirow[t]{2}{*}{ TFE } & DAP & $9.6 \pm 0.5$ & 81.6 & $3.9 \pm 0.2$ & 12.4 \\
\hline & BUTP & $9.4 \pm 0.7$ & 80.0 & $4.9 \pm 0.1$ & 15.5 \\
\hline \multirow[t]{2}{*}{ SBP } & DAP & $0.9 \pm 0.0$ & 83.0 & $4.5 \pm 0.1$ & 15.9 \\
\hline & BUTP & $0.8 \pm 0.0$ & 74.5 & $5.8 \pm 0.3$ & 20.2 \\
\hline \multirow[t]{2}{*}{ BEW } & DAP & $11.3 \pm 0.9$ & 81.6 & $2.3 \pm 0.4$ & 5.5 \\
\hline & BUTP & $10.9 \pm 0.4$ & 78.4 & $3.3 \pm 0.7$ & 7.8 \\
\hline \multirow[t]{2}{*}{$\mathrm{JCW}$} & DAP & $2.9 \pm 0.1$ & 65.3 & $2.5 \pm 0.1$ & 6.0 \\
\hline & BUTP & $3.0 \pm 0.0$ & 66.8 & $3.7 \pm 0.2$ & 9.2 \\
\hline \multirow[t]{2}{*}{ EUW } & DAP & $8.5 \pm 0.4$ & 64.3 & $3.6 \pm 0.6$ & 7.6 \\
\hline & BUTP & $8.5 \pm 0.2$ & 64.7 & $4.4 \pm 0.5$ & 9.5 \\
\hline \multirow[t]{2}{*}{ SCB } & DAP & $9.1 \pm 0.2$ & 55.3 & $3.5 \pm 0.0$ & 8.3 \\
\hline & BUTP & $11.9 \pm 0.3$ & 72.9 & $4.6 \pm 0.2$ & 10.8 \\
\hline
\end{tabular}

${ }^{a} \mathrm{~g}$ of recovered anhydro carbohydrate per $\mathrm{g}$ of input untreated dry biomass. ${ }^{b} \mathrm{~g}$ of recovered anhydro carbohydrate per g of the initial respective polymer. 
solids from both pretreatment methods. The saccharification yield at a load of 6.6 FPU g ${ }^{-1}$ of Cellic CTec2 is presented in Figure 6 . In addition, the percentage of hydrolyzed cellulose

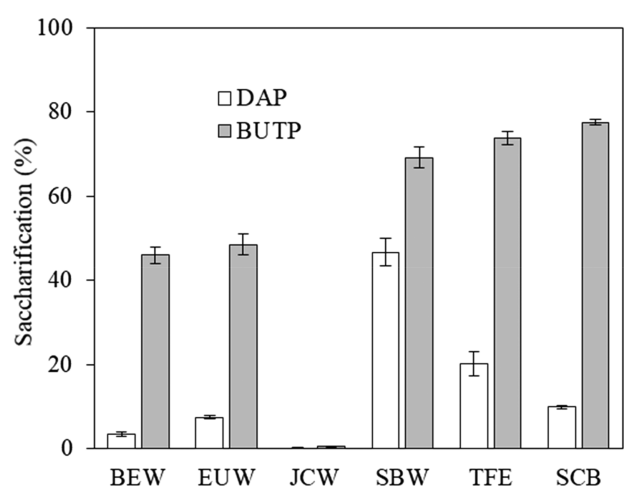

Figure 6. Saccharification percentage of cellulosic residue after DAP and BUTP.

has been calculated using the average content of hydrolyzed cellulose over the native cellulose content for each pretreated biomass. Delignification achieved by BUTP significantly improves the enzymatic saccharification yield, although almost no improvement from BUTP was observed on JCW due to its low delignification rate (12\%). The high quantity of lignin, composed mostly of G-units, is considered to be responsible for the high recalcitrance of softwoods such as Japanese cedar (more than $30 \%$ lignin). ${ }^{20,22}$ A delignification rate of $87 \%$ achieved by BUTP of SCB improved the saccharification of this biomass to $77.5 \pm 0.7 \%$ from $9.9 \pm 0.4 \%$ achieved after DAP, the best improvement in saccharification achieved in this experiment, corresponding to a cellulose hydrolysis of $96 \%$ (Table S2). Saccharification of cellulose from both hardwoods was less effective (65\% cellulose hydrolysis), probably because hardwood is a more recalcitrant material due to residual lignin and the redeposition acting as barrier. SBP contains a low lignin amount so the efficiency of saccharification does not change as drastically in response to delignification as was observed with the other biomasses. After DAP, it was already possible to achieve $46.7 \pm 3.3 \%$ saccharification, while BUTP allowed $69.01 \pm 2.5 \%$ saccharification, corresponding to $100 \%$ conversion of cellulose to glucose. BUTP also permitted 73.7 $\pm 1.5 \%$ saccharification of TFE, corresponding to $100 \%$ cellulose hydrolysis. These results are promising, being similar to (SCB: 96\%) or even higher than (TFE, SBP: 100\%) data obtained by Amiri and Karimi on cotton fibers (95.4\%), using $5 \mathrm{FPU} / \mathrm{g}$ cellulase and $10 \mathrm{IU} / \mathrm{g} \beta$-glucosidase after organosolv treatment dedicated to cellulose solubilization. ${ }^{55}$

\section{CONCLUSIONS}

BUTP is a versatile and promising technique for the efficient fractionation of various biomasses (hardwood, bagasse, herbaceous). Overall, cellulose and lignin produced by BUTP were purer and of better quality than when produced in the absence of butanol (DAP), except for Japanese cedar, which was too recalcitrant. Significant improvements were obtained on agricultural residues (sugar beet pulp, sugar cane bagasse) and dedicated crops (tall fescue). Up to 87\% delignification was achieved through BUTP, drastically decreasing lignin deposition. Lignin was recovered from the butanol with up to $96 \%$ purity, leaving an enriched cellulose fraction ( $81 \%$ cellulose in the solid residue). Organic compounds acting as fermentation inhibitors such as acetic acid, formic acid, 5hydroxymethyl furfural (5-HMF), and 2-furfural were partially solubilized in the butanol, decreasing the concentration in the aqueous phase. Enzymatic saccharification of samples was significantly improved by butanol addition, especially in the case of sugar cane bagasse (increased from 18.7\% (DAP) to 96\% (BUTP)). BUTP was more efficient on hardwood than softwood, for which optimization is still needed.

\section{ASSOCIATED CONTENT}

\section{Supporting Information}

The Supporting Information is available free of charge on the ACS Publications website at DOI: 10.1021/acssuschemeng.8b05841.

Figure S1.1-18. 2D-HSQC NMR spectra of lignin from SCB, JCW, BEW, EUW, TFE, and SBP (PDF)

Figure S2, amount of inhibitors of fermentation in aqueous phase from DAP and BUTP and in butanol phases; Table S1, composition of the precipitate recovered from the butanol fraction; Table S2, yield of enzymatic saccharification performed on cellulosic residue (PDF)

\section{AUTHOR INFORMATION}

\section{Corresponding Author}

*Tel.: +32-81-622-694. Fax: +32-81-622-231. E-mail: qschmetz@uliege.be.

\section{ORCID}

Aurore Richel: 0000-0002-4352-6542

Chiaki Ogino: 0000-0002-8906-7724

Akihiko Kondo: 0000-0003-1527-5288

\section{Funding}

The authors are grateful for the financial support of the Walloon Region in the frame of the "Wallonie-2020.EU" FEDER 2014-2020 program, "Tropical Plant Factory814687-481490.”

\section{Notes}

The authors declare no competing financial interest.

\section{ACKNOWLEDGMENTS}

The authors thank Virginie Byttebier for technical assistance, Christian Damblon for HSQC-NMR analysis and David Dundas for English proofreading.

\section{REFERENCES}

(1) Langeveld, H.; Sanders, J.; Meeusen, M. The Biobased Economy: Biofuels, Materials and Chemicals in the Post-Oil Era; Earthscan Routledge: Abingdon, U.K., 2012.

(2) Kamm, B. Biorefineries - their scenarios and challenges. Pure Appl. Chem. 2014, 86, 821-831.

(3) Lucia, L. A. Lignocellulosic biomass; a potential feedstock to replace petroleum. Bioresources 2008, 3, 981-982.

(4) Octave, S.; Thomas, D. Biorefinery: Toward an industrial metabolism. Biochimie 2009, 91, 659-664.

(5) Ben Fradj, N.; Jayet, P. A.; Aghajanzadeh-Darzi, P. Competition between food, feed, and (bio)fuel: A supply-side model based assessment at the European scale. Land Use Policy 2016, 52, 195-205.

(6) Schmetz, Q.; Maniet, G.; Jacquet, N.; Teramura, H.; Ogino, C.; Kondo, A.; Richel, A. Comprehension of an organosolv process for lignin extraction on Festuca arundinacea and monitoring of the cellulose degradation. Ind. Crops Prod. 2016, 94, 308-317. 
(7) Kumar, P.; Barrett, D.; Delwiche, M.; Stroeve, P. Methods for pretreatment of lignocellulosic biomass for efficient hydrolysis and biofuel production. Ind. Eng. Chem. Res. 2009, 48, 3713-3729.

(8) Mosier, N.; Wyman, C.; Dale, B.; Elander, R.; Lee, Y. Y.; Holtzapple, M.; Ladisch, M. Features of promising technologies for pretreatment of lignocellulosic biomass. Bioresour. Technol. 2005, 96, 673-686.

(9) Sarkar, N.; Ghosh, S. K.; Bannerjee, S.; Aikat, K. Bioethanol production from agricultural wastes: An overview. Renew. Energy 2012, 37, 19-27.

(10) Zhao, X.; Zhang, L.; Liu, D. Biomass recalcitrance. Part I: the chemical compositions and physical structures affecting the enzymatic hydrolysis of lignocellulose. Biofuels, Bioprod. Biorefin. 2012, 6, 465482.

(11) Schutyser, W.; Renders, T.; Van den Bosch, S.; Koelewijn, S.-F.; Beckham, G. T.; Sels, B. F. Chemicals from lignin: an interplay of lignocellulose fractionation, depolymerisation, and upgrading. Chem. Soc. Rev. 2018, 47, 852-908.

(12) Zimmermann, C. J.; Bollar, N. V.; Wettstein, S. G. Liquid phase conversion of lignocellulosic biomass using biphasic systems. Biomass Bioenergy 2018, 118, 163-171.

(13) Zhu, J. Y.; Pan, X.; Zalesny, R. S. Pretreatment of woody biomass for biofuel production: Energy efficiency, technologies, and recalcitrance. Appl. Microbiol. Biotechnol. 2010, 87, 847-857.

(14) Maniet, G.; Schmetz, Q.; Jacquet, N.; Temmerman, M.; Gofflot, S.; Richel, A. Effect of steam explosion treatment on chemical composition andcharacteristic of organosolv fescue lignin. Ind. Crops Prod. 2017, 99, 79-85.

(15) Teramura, H.; Sasaki, K.; Oshima, T.; Matsuda, F.; Okamoto, M.; Shirai, T.; Kawaguchi, H.; Ogino, C.; Hirano, K.; Sazuka, T.; Kitano, H.; Kikuchi, J.; Kondo, A. Organosolv pretreatment of sorghum bagasse using a low concentration of hydrophobic solvents such as 1-butanol or 1-pentanol. Biotechnol. Biofuels. 2016, 9, 27.

(16) Renders, T.; Cooreman, E.; Van den Bosch, S.; Schutyser, W.; Koelewijn, S.-F.; Vangeel, T.; Deneyer, A.; Van den Bossche, G.; Courtin, C. M.; Sels, B. F. Catalytic lignocellulose biorefining in nbutanol/water: a one-pot approach toward phenolics, polyols, and cellulose. Green Chem. 2018, 20, 4607-4619.

(17) Ezeji, T. C.; Qureshi, N.; Blaschek, H. P. Bioproduction of butanol from biomass: from genes to bioreactors. Curr. Opin. Biotechnol. 2007, 18, 220-227.

(18) Niemistö, J.; Saavalainen, P.; Pongrácz, E.; Keiski, R. L. Biobutanol as a potential sustainable biofuel - Assessment of lignocellulosic and waste-based feedstocks. J. S. D. E. W. E. S. 2013, $1,58-77$.

(19) Nielsen, D. R.; Leonard, E.; Yoon, S. H.; Tseng, H. C.; Yuan, C.; Prather, K. L. J. Engineering alternative butanol production platforms in heterologous bacteria. Metab. Eng. 2009, 11, 262-273.

(20) Ghose, T.; Pannir Selvam, P.; Ghosh, P. Catalytic solvent delignification of agricultural 464 residues: organic catalysts. Biotechnol. Bioeng. 1983, 25, 2577-2590.

(21) Himmel, M.; Ding, S. Y.; Johnson, D. K.; Adney, W. S.; Nimlos, M. R.; Brady, J. W.; Foust, T. D. Biomass Recalcitrance: Engineering Plants and Enzymes for Biofuels Production. Science 2007, 315 (5813), 804-807.

(22) Studer, M. H.; DeMartini, J. D.; Davis, M. F.; Sykes, R. W.; Davison, B.; Keller, M.; Tuskan, G. A.; Wyman, C. E. Lignin content in natural Populus variants affects sugar release. Proc. Natl. Acad. Sci. U. S. A. 2011, 108 (15), 6300-6305.

(23) Matsuda, F.; Yamasaki, M.; Hasunuma, T.; Ogino, C.; Kondo, A. Variation in biomass properties among rice diverse cultivars. Biosci., Biotechnol., Biochem. 2011, 75, 1603-1608.

(24) Sluiter, A.; Hames, B.; Ruiz, R.; Scarlata, C.; Sluiter, J.; Templeton, D. Determination of Ash in Biomass: Laboratory Analytical Procedure (LAP); issue date, July 2005; NREL: Golden, CO, 2008; pp $1-5$

(25) Sluiter, A.; Ruiz, R.; Scarlata, C.; Sluiter, J.; Templeton, D. Determination of Extractives in Biomass: Laboratory Analytical
Procedure (LAP); issue date, 2005; NREL: Golden, CO, 2008; pp $1-9$

(26) Tkachuk, R. Nitrogen to protein conversion factors for cereals and oilseed meals. Cereal Chem. 1969, 46, 419-424.

(27) Sluiter, A.; Hames, B.; Ruiz, R.; Scarlata, C.; Sluiter, J.; Templeton, D.; Crocker, D. Determination of Structural Carbohydrates and Lignin in Biomass: Laboratory Analytical Procedure (LAP); issue, 2008; revision, 2012; NREL: Golden, CO, 2012; pp 1-15.

(28) TAPPI UM 250. Acid-soluble lignin in wood and pulp. In TAPPI Useful Methods; Tappi: Atlanta, GA, 1991.

(29) Sakamoto, T.; Hasunuma, T.; Hori, Y.; Yamada, R.; Kondo, A. Direct ethanol production from hemicellulosic materials of rice straw by use of an engineered yeast strain codisplaying three types of hemicellulolytic enzymes on the surface of xylose-utilizing Saccharomyces cerevisiae cells. J. Biotechnol. 2012, 158, 203-210.

(30) Sasaki, K.; Tsuge, Y.; Sasaki, D.; Teramura, H.; Inokuma, K.; Hasunuma, T.; Ogino, C.; Kondo, A. Mechanical milling and membrane separation for increased ethanol production during simultaneous saccharification and co-fermentation of rice straw by xylose-fermenting Saccharomyces cerevisiae. Bioresour. Technol. 2015, $185,263-268$

(31) Neiva, D.; Fernandes, L.; Araújo, S.; Lourenço, A.; Gominho, J.; Simões, R.; Pereira, H. Chemical composition and kraft pulping potential of 12 eucalypt species. Ind. Crops Prod. 2015, 66, 89-95.

(32) Szczerbowski, D.; Pitarelo, A. P.; Zandona Filho, A.; Ramos, L. P. Sugarcane biomass for biorefineries: Comparative composition of carbohydrate and non-carbohydrate components of bagasse and straw. Carbohyd. Polym. 2014, 114, 95-101.

(33) Simon, M.; Brostaux, Y.; Vanderghem, C.; Jourez, B.; Paquot, M.; Richel, A. Optimization of a formic/acetic acid delignification treatment on beech wood and its influence on the structural characteristics of the extracted lignins. J. Chem. Technol. Biotechnol. 2014, 89, 128-136.

(34) Sagehashi, M.; Miyasaka, N.; Shishido, H.; Sakoda, A. Superheated steam pyrolysis of biomass elemental components and Sugi (Japanese cedar) for fuels and chemicals. Bioresour. Technol. 2006, 97, 1272-1283.

(35) Bellido, C.; Infante, C.; Coca, M.; González-Benito, G.; Lucas, S.; García-Cubero, M. T. Efficient acetone-butanol-ethanol production by Clostridium beijerinckii from sugar beet pulp. Bioresour. Technol. 2015, 190, 332-338.

(36) Njoku, S. I.; Ahring, B. K.; Uellendahl, H. Pretreatment as the crucial step for a cellulosic ethanol biorefinery: Testing the efficiency of wet explosion on different types of biomass. Bioresour. Technol. 2012, 124, 105-110.

(37) Hu, F.; Jung, S.; Ragauskas, A. Pseudo-lignin formation and its impact on enzymatic hydrolysis. Bioresour. Technol. 2012, 117, 7-12.

(38) Selig, M. J.; Viamajala, S.; Decker, S. R.; Tucker, M. P.; Himmel, M. E.; Vinzant, T. B. Deposition of lignin droplets produced during dilute acid pretreatment of maize stems retards enzymatic hydrolysis of cellulose. Biotechnol. Prog. 2007, 23, 1333-1339.

(39) Kärcher, M. A.; Iqbal, Y.; Lewandowski, I.; Senn, T. Efficiency of single stage- and two stage pretreatment in biomass with different lignin content. Bioresour. Technol. 2016, 211, 787-791.

(40) Norman, A.; Jenkins, S. The determination of lignin. II. Errors introduced by the presence of proteins. Biochem. J. 1934, 28, 21602168.

(41) Kawamata, Y.; Yoshikawa, T.; Nakasaka, Y.; Koyama, Y.; Fumoto, E.; Sato, S.; Tago, T.; Masuda, T. Organosolv Treatment Using 1-Butanol and Degradation of Extracted Lignin Fractions into Phenolic Compounds over Iron Oxide Catalyst. J. Jpn. Pet. Inst. 2019, $62,37-44$.

(42) del Rio, J. C.; Prinsen, P.; Rencoret, J.; Nieto, L.; JimenezBarbero, J.; Ralph, J.; Martinez, A. T.; Gutierrez, A. Structural characterization of the lignin in the cortex and pith of elephant grass (Pennisetum purpureum) stems. J. Agric. Food Chem. 2012, 60, 3619-3634.

(43) del Rio, J. C.; Lino, A. G.; Colodette, J. L.; Lima, C. F.; Gutierrez, A.; Martinez, A. T.; Lu, F.; Ralph, J.; Rencoret, J. 
Differences in the chemical structure of the lignins from sugarcane bagasse and straw. Biomass Bioenerg. 2015, 81, 322-338.

(44) Fernández-Costas, C.; Gouveia, S.; Sanromán, M. A.; Moldes, D. Structural characterization of Kraft lignins from different spent cooking liquors by $1 \mathrm{D}$ and 2D Nuclear Magnetic Resonance spectroscopy. Biomass Bioenergy 2014, 63, 156-166.

(45) Kim, H.; Ralph, J. Solution-state 2D NMR of ball-milled plant cell wall gels in DMSO $\mathrm{d}_{6} /$ pyridine- $\mathrm{d}_{5}$. Org. Biomol. Chem. 2010, 8, 576-591.

(46) Samuel, R.; Foston, M.; Jiang, N.; Allison, L.; Ragauskas, A. J. Structural changes in switchgrass lignin and hemicelluloses during pretreatments by NMR analysis. Polym. Degrad. Stab. 2011, 96, 2002-2009.

(47) Villaverde, J. J.; Li, J.; Ek, M.; Ligero, P.; De Vega, A. Native lignin structure of Miscanthus $\mathrm{x}$ giganteus and its changes during acetic and formic acid fractionation. J. Agric. Food Chem. 2009, 57, $6262-6270$.

(48) Vanderghem, C.; Richel, A.; Jacquet, N.; Blecker, C.; Paquot, $\mathrm{M}$. Impact of formic/acetic acid and ammonia pre-treatments on chemical structure and physic-chemical properties of Miscanthus $x$ giganteus lignins. Polym. Degrad. Stab. 2011, 96, 1761-1170.

(49) Wen, J.-L.; Xue, B.-L.; Xu, F.; Sun, R.-C.; Pinkert, A. Unmasking the structural features and property of lignin from bamboo. Ind. Crops Prod. 2013, 42, 332-343.

(50) Yuan, T.-Q.; Sun, S.-N.; Xu, F.; Sun, R.-C. Characterization of lignin structures and lignin-carbohydrate complex (LCC) linkages by quantitative 13C and 2D HSQC NMR spectroscopy. J. Agric. Food Chem. 2011, 59, 10604-10614.

(51) Zhang, Y.; Wu, J.-Q.; Li, H.; Yuan, T.-Q.; Wang, Y.-Y.; Sun, R.C. Heat Treatment of Industrial Alkaline Lignin and its Potential Application as an Adhesive for Green-Wood-Lignin Composites. ACS Sustainable Chem. Eng. 2017, 5, 7269-7277.

(52) Leijdekkers, A.; Bink, J.; Geutjes, S.; Schols, H.; Gruppen, H. Enzymatic saccharification of sugar beet pulp for the production of galacturonic acid and arabinose; a study on the impact of the formation of recalcitrant oligosaccharides. Bioresour. Technol. 2013, $128,518-525$.

(53) Papa, G.; Varanasi, P.; Sun, L.; Cheng, G.; Stavila, V.; Holmes, B.; Simmons, B. A.; Adani, F.; Singh, S. Exploring the effect of different plant lignin content and composition on ionic liquid pretreatment efficiency and enzymatic saccharification of Eucalyptus globulus L. mutants. Bioresour. Technol. 2012, 117, 352-359.

(54) Li, X.; Li, M.; Pu, Y.; Ragauskas, A.; Klett, A.; Thies, M.; Zheng, Y. Inhibitory effects of lignin on enzymatic hydrolysis: The role of lignin chemistry and molecular weight. Renewable Energy 2018, 123, 664-674.

(55) Amiri, H.; Karimi, K. Efficient Dilute-Acid Hydrolysis of Cellulose Using Solvent Pretreatment. Ind. Eng. Chem. Res. 2013, 52, 11494-11501. 